IZA DP No. 5413

Smart and Dangerous: How Cognitive Skills Drive the Intergenerational Transmission of Retaliation

Ruby Henry

December 2010 


\title{
Smart and Dangerous: How Cognitive Skills Drive the Intergenerational Transmission of Retaliation
}

\author{
Ruby Henry \\ $I Z A$
}

\section{Discussion Paper No. 5413 \\ December 2010}

\author{
IZA \\ P.O. Box 7240 \\ 53072 Bonn \\ Germany \\ Phone: +49-228-3894-0 \\ Fax: +49-228-3894-180 \\ E-mail: iza@iza.org
}

Any opinions expressed here are those of the author(s) and not those of IZA. Research published in this series may include views on policy, but the institute itself takes no institutional policy positions.

The Institute for the Study of Labor (IZA) in Bonn is a local and virtual international research center and a place of communication between science, politics and business. IZA is an independent nonprofit organization supported by Deutsche Post Foundation. The center is associated with the University of Bonn and offers a stimulating research environment through its international network, workshops and conferences, data service, project support, research visits and doctoral program. IZA engages in (i) original and internationally competitive research in all fields of labor economics, (ii) development of policy concepts, and (iii) dissemination of research results and concepts to the interested public.

IZA Discussion Papers often represent preliminary work and are circulated to encourage discussion. Citation of such a paper should account for its provisional character. A revised version may be available directly from the author. 
IZA Discussion Paper No. 5413

December 2010

\section{ABSTRACT}

\section{Smart and Dangerous: How Cognitive Skills Drive the Intergenerational Transmission of Retaliation}

A need exists to understand how people develop an aggressive, retaliatory conflict resolution policy vs. a more passive reconciliation stance. I contribute a choice-theoretic model that explains how cognitive skills drive the transmission of conflict resolution policies. A child's resolution policy depends on parental effort and the influence of the outside environment. The model has the implication that high-cognitive parents socialize children to their conflict resolution culture more successfully than parents with low cognitive skills. Indeed, I test the model using the cognitive skills and conflict resolution skills of parents and children from the UK National Childhood Development Survey. I find that the parent's effort is reinforced by the prevalence of their conflict resolution values in society. The data confirm that children of retaliating high-cognitive parents are more likely to be socialized to that resolution culture than children of low-cognitive retaliating parents when retaliation is more prominent in society.

JEL Classification: D10, I20, J13

Keywords: socioemotional skills, cultural transmission, family influence

Corresponding author:

Ruby Henry

IZA

P.O. Box 7240

53072 Bonn

Germany

E-mail: rhenry@iza.org 


\section{Introduction}

A need exists to understand how people adopt an aggressive retaliation stance vs. a passive reconciliation stance when an offense arises. ${ }^{1} \quad$ The conflict resolution stance one adopts when interacting with others fits into the broader category of socioemotional skills. Economic research continues to document the importance of noncognitive, or socioemotional, skills. These skills affect adult outcomes as strongly as cognitive skills (Heckman and Carneiro [2003]). I find that cognitive skills are not particularly associated with a retaliation or a reconciliation approach to conflict, and I show that socioemotional skills are more malleable than cognitive skills.

For these reasons, I believe the shaping of socioemotional skills deserves increased attention, and I contribute a choice-theoretic model which explains the development of, or "socialization" to, a certain socioemotional skill. I focus on a new dimension of socialization: the outcome of a retaliatory stance, or "culture," as it is commonly referred to in the sociology literature. In the model, this outcome depends both on the influence of the parent and the outside environment, which draws from the recent economic literature on internal and external socialization spurred by Bisin and Verdier [2001]. Parents evaluate the two available cultures with their own preferences. Consequently, parents choose an effort level with which to teach children their own culture, believing it is the "right" one. In the model, relatively aggressive parents aim to socialize their children to the aggressive retaliation culture. Less aggressive parents teach a forgiveness culture. Finally, the parents' cognitive ability affects the quality of their effort.

That said, the greater community also impacts the child's outcome. In fact, this paper departs from the recent cultural transmission literature (see Bisin, Topa, and Verdier [2004], Patacchini and Zenou [2007]) by lending greater importance to the outside environment. In this setting, the parent's effort cannot succeed without minimal reinforcement

\footnotetext{
${ }^{1}$ I will use the following words within brackets interchangeably: \{forgiving, reconciling, passive, nonaggressive\}, \{aggressive, retaliatory\}, \{socioemotional culture, conflict resolution culture, culture $\}$.
} 
from society. In the previous literature, children could bump into peers, for example, and become socialized to a culture different than the one taught by their parents. A distinguishing feature of the retaliation vs. forgiveness dimension is the added implications when these run-ins include conflicts. In a conflict, a forgiving person faces a higher probability of being retaliated against when more people are retaliators, even though the forgiving person will forgive. In this sense, the presence of retaliating people yields a negative externality for forgiving people. In the same way, the presence of forgiving people results in a positive externality for retaliators. In a conflict with a forgiving person, a retaliator will not suffer punishment. Thus, the greater the presence of forgiving people in society, the lower the probability a retaliating person will be retaliated against.

When the parent's culture is more prominent in society, these externalities enhance the effort of the parent, or "grease the wheels of indoctrination", so to speak. Persuading a child to be forgiving is easier the lower the probability they will be retaliated against. Similarly, convincing a child to adopt a retaliation policy is easier the more they feel they will be retaliated against. The data support this complementarity between the parent's effort and the prominence of the parent's culture in the outside environment.

I test the model with parent-child records in the UK National Childhood Development Survey (NCDS). Parent's socialization effort is a strong determinant of the child's cultural outcome. I also find that parental effort is enhanced by the prevalence of the parent's culture in society. Cognition affects this process. In particular, when an aggressive culture is more prominent in society, high-cognitive aggressive parents increase their effort investment less than low-cognitive aggressive parents, yet the probability that an aggressive parent successfully socializes the child to an aggressive retaliation culture increases more for a high-cognitive parent than for a low-cognitive parent.

I now provide evidence of the need to reshape resolution cultures and that conflict resolution skills are more malleable than cognitive skills. This lends an opportunity for parents and society to intervene. 


\section{Opportunity to Reshape Resolution Cultures}

A certain degree of aggression is necessary to commit a violent act. The young U.S. population is actually shrinking, yet violent crimes attributed to this age group are increasing (See Chart 1).

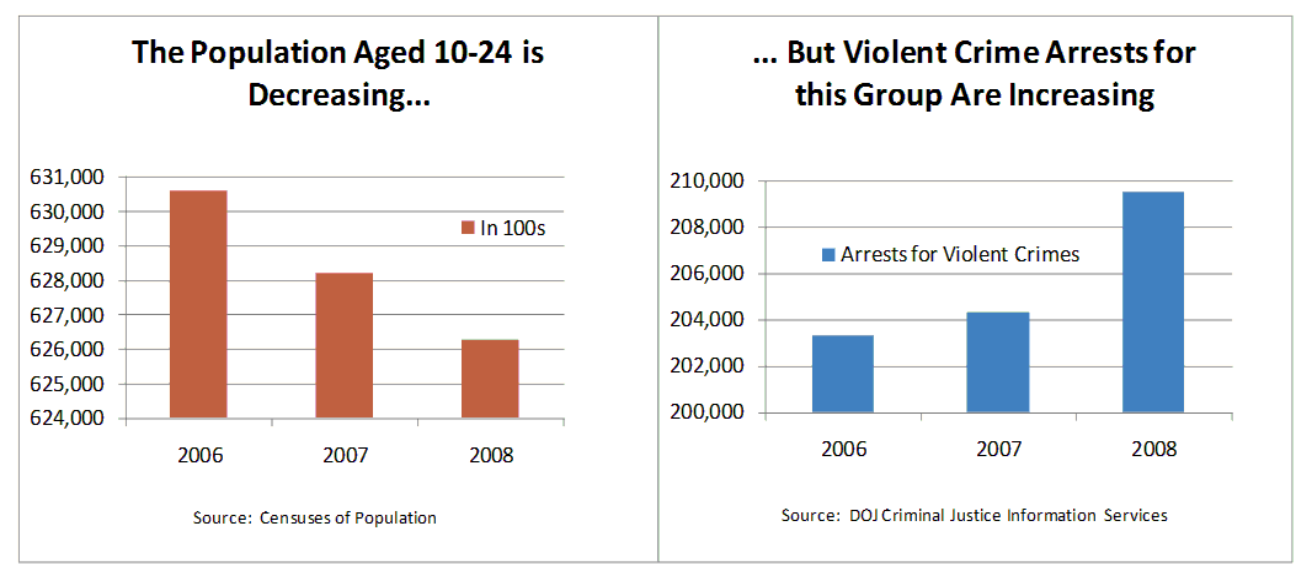

Chart 1

I find, however that aggressive behavior during youth can change. Furthermore, it is important to know that aggression is more pliant than cognitive skills.

A set of transition matrices for positions in the distribution of cognitive skill and aggression, respectively, provides this insight (See Tables 1, 2). ${ }^{2}$ The probability of a child remaining in the same part of the cognitive skill distribution is over .70 for every level of cognitive skills. In contrast, those with more aggression initially do move to different points in the distribution of aggression with high probability. In addition, it is not possible to rise to the top of the cognitive skill distribution if one started at the bottom. It is also impossible to fall to the bottom of the cognitive skill distribution if one started at the top. This is not true for aggression. Half the people who start out as

\footnotetext{
${ }^{2}$ Cognitive skills are measured by math and reading standardized tests. Groups in Table 2 reflect the degree of aggression exhibited in the child's behavior. See Section 5.1 for a detailed description of aggression.
} 
highly aggressive move to a point of low aggression. In addition, one-fifth of those who start with low aggression become highly aggressive.

\begin{tabular}{c|c|ccc}
\hline \multicolumn{5}{c|}{ Cognitive Group at Age $16 \longrightarrow$} \\
\multicolumn{2}{l|}{} & Lo C & Mid C & Hi C \\
\hline Group & Lo C & 0.72 & 0.28 & 0.00 \\
at & Mid C & 0.13 & 0.74 & 0.13 \\
Age 11 & Hi C & 0.00 & 0.27 & 0.73 \\
\hline \multicolumn{5}{l}{ Source: Author's tabulation of NCDS. } \\
\hline \hline
\end{tabular}

Table 1: Transitions in the Distribution of Cognitive Skills

\begin{tabular}{c|c|ccc}
\hline \hline \multicolumn{5}{c}{ Aggression Group at Age 16 } \\
\multicolumn{2}{l}{} & Lo A & Mid A & Hi A \\
\hline Group & Lo A & 0.76 & 0.04 & 0.20 \\
at & Mid A & 0.73 & 0.09 & 0.17 \\
Age 11 & Hi A & 0.53 & 0.16 & 0.31 \\
\hline
\end{tabular}

Source: Author's tabulation of NCDS.

Table 2: Transitions in the Distribution of Aggression

Less stickiness in the evolution of aggression relative to that of cognitive skills suggests an opportunity to influence the former. I now propose a theory for the active shaping of socioemotional skills in children which is driven by fixed cognitive skills of their parents.

\section{A Theory of Socioemotional Skill Transmission}

\subsection{Setting}

There are two generations, parent and child. Parents, the only active players, decide on a time allocation of (Labor, Leisure, Child Rearing). Their payoff is the sum of (1) present 
utility from income, leisure, and child rearing effort and (2) the future utility of children.

Parents evaluate conflict resolution approaches with their own preferences. Thus, they believe their way is the "right" way and that their children will be better off if they have the same culture as they do. Ultimately, the culture of the parent determines the cultural content of the effort they exert. Retaliation is one type of culture represented in this phrase: "Fracture for fracture, eye for eye, tooth for tooth; whatever injury he has given a person shall be given to him." Forgiveness, the other culture, rejects this type of resolution: "You have heard that it was said, 'An eye for an eye, and a tooth for a tooth': But I say to you, ... if anyone slaps you on the right cheek, turn to him the other also."

The culture of retaliation has aggressive undertones, while a culture of forgiveness necessitates a degree of nonaggression. Aggressive parents use the child rearing time to teach "an eye for an eye." Nonaggressive parents spend their child rearing time instilling "turn the other cheek." This time investment cultivates the aggression (nonaggression) necessary for children to adopt the retaliation (forgiveness) culture. ${ }^{3}$

The share of society allied with the parent's culture enhances the parent's effort. Successful socialization requires some reinforcement from the outside environment. Socializing children to be forgiving has greater sway the lower the probability they will conflict with a retaliating person. Similarly, convincing children to retaliate is easier the greater the potential of being a victim of retaliation.

Finally, the effort of high cognitive skill parents is considered higher quality. Otherwise stated, high-cognitive parents are better teachers.

\footnotetext{
${ }^{3}$ An assumption, is that although the parent's effort influences socioemotional skills, the child does not react to the plain fact that the parent has made an effort; there is no rebellion or pleasing.
} 


\subsection{Model}

\subsubsection{Skill Sets}

The two levels of cognitive skills $(c)$ are High $(H)$ and Low $(L), c \in\{H, L\}$. There are two types $(i)$ of socioemotional cultures: Forgiving-Passive $(P)$ and Retaliatory-Aggressive $(A), i \in\{A, P\}$.

The exogenous share of people outside the home environment (e.g. school, neighborhood) with Retaliatory-Aggressive skills is $q \in[0,1]$.

\subsubsection{Socialization Probabilities to a Conflict Resolution Culture}

Parents use their effort-time, $e^{i} \in[0,1]$, to influence the child's cultural outcome. Recall that the effort of low cognitive skill parents is discounted by $\delta \in[0,1)$. The probability that a parent with socioemotional culture $i$ and cognitive skill level $c$ will have a child that develops socioemotional culture $i$ is $\pi_{i c}^{i}$, the probability of successful socialization:

$$
\begin{aligned}
& \pi_{A H}^{A}=q e^{A} \\
& \pi_{A L}^{A}=q \delta e^{A}
\end{aligned}
$$

The equations above reflect that an aggressive parent's success probability depends on their effort $e^{A}$, which is complemented by the prevalence of their beliefs in the outside environment. ${ }^{4} \pi_{A H}^{A}>\pi_{A L}^{A}$ implies that aggressive high cognitive skill parents "win" more frequently than their low cognitive skill counterparts for a given level of effort.

The socialization probabilities for passive parents are similar:

$$
\begin{aligned}
\pi_{P H}^{P} & =(1-q) e^{P} \\
\pi_{P L}^{P} & =(1-q) \delta e^{P}
\end{aligned}
$$

$$
{ }^{4} \pi_{A c}^{P}=1-\pi_{A c}^{A}
$$


A passive parent's success is a function of their effort level enhanced by the degree to which the child's sphere of influence shares the same culture. ${ }^{5} \quad \pi_{P H}^{P}>\pi_{P L}^{P}$ again reflects the higher quality effort of high cognitive skill parents.

\subsubsection{Utility}

The present utility of a parent is:

$$
U\left(\lambda^{i}\right)
$$

where $\lambda^{i}$ is leisure time. Total time is normalized to 1 , thus $\lambda^{i}=1-e^{i}$.

The cost of effort, $\kappa(e)$, is utility from leisure:

$$
\kappa(e)=-U(1-e)
$$

I assume that the marginal cost of effort is positive,

$$
\kappa^{\prime}(e)=U^{\prime}(1-e)>0
$$

and increasing,

$$
\kappa^{\prime \prime}(e)=-U^{\prime \prime}(1-e)>0
$$

A type $i$ parent's perception of the future utility for a type $i$ child is $W_{i}^{i}{ }^{6}$ Again, parents believe that children will be better off if they have the same culture as they do: $W_{i}^{i}>W_{j}^{i}$. The future utility of the child enters into the parent's expected utility. I normalize $W_{j}^{i}$ to 0 , and $W_{i}^{i}$ is the incremental utility from having a "like" child. For simplicity, the weights on present utility and the child's future utility are equal.

${ }^{6}$ For simplicity I consider future utility from socioemotional culture only. This is the only relevant aspect of utility in the parents' optimization decision as they cannot change cognitive skills.
} 


\subsection{Choosing Effort Level}

Aggressive and passive parents maximize expected utility

$$
\begin{aligned}
& E V_{c}^{A}=U\left(1-e^{A}\right)+\pi_{A c}^{A} W_{A}^{A} \\
& E V_{c}^{P}=U\left(1-e^{P}\right)+\pi_{P c}^{P} W_{P}^{P}
\end{aligned}
$$

subject to

$$
\begin{aligned}
& \pi_{A c}^{A}=q \delta^{c} e^{A} \\
& \pi_{P c}^{P}=(1-q) \delta^{c} e^{P},
\end{aligned}
$$

respectively, where $\delta^{H}=1$ and $\delta^{L}=\delta$.

The F.O.C.'s are:

$$
\begin{aligned}
-U^{\prime}\left(1-e^{A}\right)+q \delta^{c} W_{A}^{A} & =0 \\
-U^{\prime}\left(1-e^{P}\right)+(1-q) \delta^{c} W_{P}^{P} & =0
\end{aligned}
$$

Defining $\Psi=\left[U^{\prime}\right]^{-1}$, the optimal effort levels $\operatorname{are}^{7}$ :

$$
\begin{aligned}
e_{c}^{A *} & =1-\Psi\left[q \delta^{c} W_{A}^{A}\right] \\
e_{c}^{P *} & =1-\Psi\left[(1-q) \delta^{c} W_{P}^{P}\right]
\end{aligned}
$$

\footnotetext{
${ }^{7}$ The assumption $\kappa^{\prime \prime}(e)>0$ implies $U^{\prime \prime}(\cdot)<0$, which ensures a maximum. $\Psi>0, \Psi^{\prime}<0$.
} 


\section{Implications for Effort and Socialization}

\section{Proposition 1}

(i) $\frac{\partial e_{c}^{A *}}{\partial q}=-\Psi^{\prime}\left[\delta^{c} q W_{A}^{A}\right] \delta^{c} W_{A}^{A}>0$

The aggressive parent's optimal effort level increases as the outside environment becomes more aggressive. This is the complementarity between the two sources of socialization. $^{8}$

(ii) $\frac{\partial e_{c}^{P *}}{\partial q}=\Psi^{\prime}\left[\delta^{c}(1-q) W_{P}^{P}\right] \delta^{c} W_{P}^{P}<0$

I interpret the implications for passive parents in terms of the population share that is passive $(1-q)$. The greater the share of passive people in the sphere of influence, the more effort passive parents exert.

The magnitude of $\frac{\partial e_{H}^{i *}}{\partial q}$ relative to $\frac{\partial e_{L}^{i *}}{\partial q}$ depends on assumptions concerning the sign of $U^{\prime \prime \prime}$, which determines whether $\Psi^{\prime}[\cdot]$ is decreasing or increasing. I refrain from making an assumption, but I will test the relative magnitudes of the $\frac{\partial e_{c}^{i *}}{\partial q}$ in the data.

\section{Proposition 2}

(i) For aggressive parents the probability their child will have aggressive socioemotional skills is: $\pi_{A c}^{A}=q \delta^{c} e_{c}^{A *}[q]$.

(ii) For passive parents the probability that their child will have passive socioemotional skills is: $\pi_{P c}^{P}=(1-q) \delta^{c} e_{c}^{P *}[q]$.

(iii) $\frac{\partial \pi_{A c}^{A}}{\partial q}>0$

When the proportion of society practicing retaliation increases, the probability of an aggressive cultural outcome increases. This arises through the direct effect of $q$ on the outcome probability and the indirect effect of $q$ increasing effort.

\footnotetext{
${ }^{8}$ See Appendix 1 for the proofs.
} 
(iv) $\frac{\partial \pi_{P c}^{P}}{\partial q}<0$

When the outside environment is more aligned with a retaliation culture, a passive parent is less likely to have a child that adopts a forgiveness culture. This is the result of the direct effect of $q$ and because an increase in $q$ also causes passive parents to decrease their effort. Equivalently, when more of society subscribes to a forgiveness culture, the probability of a forgiving parent successfully socializing his or her child increases.

The magnitude of $\frac{\partial \pi_{i H}^{i}}{\partial q}$ relative to $\frac{\partial \pi_{i L}^{i}}{\partial q}$ also depends on assumptions concerning the sign of $U^{\prime \prime \prime}$ because these probabilities depend on $\frac{\partial e_{H}^{i *}}{\partial q}$ and $\frac{\partial e_{L}^{i *}}{\partial q}$ respectively. Again, these relative magnitudes are testable.

\section{Testing the Model's Implications}

A number of testable implications are presented in the Propositions above. Testing requires suitable measures of $q, e$, and skill type $(c, i)$ for parents and children. I use the UK NCDS panel survey. The first three waves include interviews of a birth cohort (Generation 1) and the parents of the cohort members (Generation 0). In the fifth wave, the children of the cohort members (Generation 2) are also interviewed. For the empirical application, Generation 1 maps to "parents" from the theoretical model and Generation 2 maps to "children" in the theoretical model.

\subsection{Identifying Cultural Alignment}

\subsubsection{Parents and Children}

Parents in Generation 0 identify their children (Generation 1) as aggressive or nonaggressive using the same rubric as Parents in Generation 1 later use to classify their children (Generation 2): 
...indicate for each one whether this description certainly applies, applies somewhat or does not apply to your child

1)He/She often destroys own or others' property.

2)He/She frequently fights or is quarrelsome with other children.

3) He/She bullies other children.

4)He/She is irritable and is quick to "fly off the handle".

The socioemotional skills of both generations are extracted from the responses of their respective parents. Those in Generation 1 and 2 with an aggressive culture are those for whom the behaviors above apply somewhat or certainly. A concern might be a bias in the responses of parents. The same questions are asked of both the parents and the teachers of Generation 1. The responses of parents and teachers are positively correlated.

\subsubsection{Outside Environment}

The exogenous share of people in a child's environment, or sphere of influence, who display an aggressive culture is $q$. The empirical counterpart is lagged 17 years. People in the outside environment with an aggressive culture are those for whom the following behaviors apply somewhat or certainly:
1)He/She often destroys own or others' property.
2)He/She frequently fights or is quarrelsome with other children.
3)He/She bullies other children.
4) He/She is irritable and is quick to "fly off the handle".

The outside environment is defined as one of 11 geographical areas. The share of those with an aggressive culture $(q)$ is shown by area $^{9}$ :

\footnotetext{
${ }^{9}$ The areas are admittedly large, however institutional restrictions prevent access to greater geographic detail at present.
} 
Table 3: The Share of Aggressive People by Area

\begin{tabular}{lll}
\hline \hline Area & $N$ & $q$ \\
\hline North & 869 & 0.21 \\
North West & 1471 & 0.18 \\
E. \& W. Riding & 882 & 0.18 \\
North Midlands & 872 & 0.16 \\
Midlands & 1129 & 0.16 \\
South West & 763 & 0.16 \\
East & 981 & 0.15 \\
South East & 1864 & 0.15 \\
Scotland & 1331 & 0.15 \\
Wales & 615 & 0.13 \\
South & 826 & 0.12 \\
\hline Source: NCDS & & \\
\hline \hline
\end{tabular}

This geographical interpretation has to at least show differences in $q$ to affect effort and socialization outcomes. Table 4 shows that this measure of $q$ differs statistically by area: 
Table 4: The Prominence of Aggression $(q)$ Differs Statistically by Area

\begin{tabular}{l}
\hline Geo. Area \\
\hline \\
\multicolumn{1}{l|}{$\downarrow$} \\
\hline \\
\hline
\end{tabular}

Source: Author's Tabulations of NCDS.

Note: $* * *, * *, *$ denote significance at the $1 \%, 5 \%, 10 \%$ level respectively 


\subsection{Cognitive Skills}

The cognitive skills of parents play a role in the model. Cognitive skills are assumed to increase the impact of the parents' effort to socialize children. Such cognitive skills are measured by achievements on standardized math and reading tests administered by the NCDS to interviewees. One may question whether cognitive skills are exogenous to retaliatory or reconciliatory behavior. This does not seem to be a real concern, however. Those exhibiting an aggressive culture fall into the same median quartile of cognitive achievement as those in the forgiving culture. The difference in the mean quartile of cognitive achievement is small: 2.7 for retaliatory people vs. 2.9 for forgiving ones. For this specific set of socioemotional skills, cognitive skills do not appear endogenous.

\subsection{Effort}

The time parents spend teaching a conflict resolution culture is unobserved and therefore proxied by other responses. Given a culture, the proxies measure the intensity of this culture in the parent's reaction to a negative experience with their child. I thereby assume that the type of culture the parents teach their children is also the type of culture the parents use to teach their children. These proxies are also justified if children learn from the way they are taught.

For aggressive parents, the following questions serve as proxies for their effort to socialize their children to retaliation:

I. If your child brought home a report with mark or comments lower than expected, how likely would you be tell him/her off?

II. If your child brought home a report with mark or comments lower than expected, how likely would you be to punish him/her?

Not at all Likely

1

2
3
Very Likely

45


For passive parents the following are proxies for their effort to socialize their children to reconciliation:

III. If your child brought home a report with mark or comments lower than expected, how likely would you be to wait and see if he/she improves on own?

IV. If your child brought home a report with mark or comments lower than expected, how likely would you be to talk with him/her?

$\begin{array}{rrrcc}\text { Not at all Likely } & & & \text { Very Likely } \\ 1 & 2 & 3 & 4 & 5\end{array}$

Though questions I-IV are asked of all parents, it is meaningful that the aggressive parents do not employ tactics in questions III and IV. Similarly, passive parents do not employ tactics in questions I and II. ${ }^{10}$

\subsection{Joint Estimation of Effort and Cultural Outcome}

\subsubsection{Specification}

Proposition 1 treated the relationship between parental time investment and the influence of the outside environment. A parent's effort, $e^{i}$, is modeled as a linear function of the prominence of aggression in the outside culture, $q$, in region of residence, $r$, and other control variables:

\footnotetext{
${ }^{10}$ This also speaks to the issue of parents perhaps having changed their culture later in life. Recall, the last time I observe socioemotional skills is at age 16. The fact that people identified as aggressive at age 16 also display aggressive behavior later with their children provides some weak evidence that socioemotional skills may become stickier with age, though they are highly malleable at younger ages. That said it may be possible that initially aggressive people remain aggressive with their children, but not in other areas. If this were true, the inability to control for it would cause the variables of interest to appear less effective than they truly are.
} 


$$
e_{n}^{i}=\alpha q_{r}+\phi z_{n}+\vec{\beta} \vec{x}_{n}+\varepsilon_{n}
$$

Implications for the socialization probabilities presented in Proposition 2 can also be tested. The $\pi_{i}^{i}$ are modeled as a linear function of $q, e^{i}$, and other control variables:

$$
\pi_{i n}^{i}=\gamma_{1} q_{r}+\gamma_{2} e_{n}^{i}+\gamma_{3}\left(q_{r} \cdot e_{n}^{i}\right)+\vec{\eta} \vec{x}_{n}+\xi_{n}
$$

The effort variable, $e_{n}^{i}$, is equal to 1 if a parent is more likely than the median parent (in that conflict resolution culture) to practice the behaviors in the respective proxy questions and 0 otherwise. $\pi_{i n}^{i}$ is equal to 1 if the child exhibits the same culture as the parent and 0 otherwise.

\subsubsection{Identification}

Because $\varepsilon_{n}$ and $\xi_{n}$ may be correlated, I estimate (12) and (13) jointly by Maximum Likelihood in a bivariate probit specification. The model is identified if one or more variables in (12) predict a parent's effort but do not cause the child's cultural outcome. This variable is represented by $z$ in (12), and is excluded from (13). The child's age at which the mother stops breast feeding and whether the child was breast-fed are significantly correlated with effort, but do not cause any factors that cause the child's socioemotional culture. Table 5 reports these relationships. 
Table 5: Exclusion Restriction

\begin{tabular}{|c|c|c|c|}
\hline & & Retaliating $^{1}$ & Forgiving \\
\hline & & Age Breast & Was Child \\
\hline & & Feeding Stopped & Breastfed \\
\hline \multirow[t]{6}{*}{$e_{i}$} & Parent Effort & $-0.0059^{* *}$ & $0.0743^{* *}$ \\
\hline & & $(0.0031)$ & $(0.0380)$ \\
\hline & Drinking & 0.0436 & -0.0012 \\
\hline & & $(0.0787)$ & $(0.0022)$ \\
\hline & Male Child & -0.0009 & 0.0295 \\
\hline & & $(0.0011)$ & $(0.0384)$ \\
\hline \multirow[t]{2}{*}{$\uparrow$} & No. of Children & -0.0027 & 0.0831 \\
\hline & & $(0.0022)$ & $(0.0663)$ \\
\hline \multirow[t]{2}{*}{$x$} & Income & -0.1649 & -0.0904 \\
\hline & & $(0.4342)$ & $(0.5428)$ \\
\hline \multirow[t]{4}{*}{$\downarrow$} & Savings & -0.3026 & 0.4005 \\
\hline & & $(0.5008)$ & $(0.2727)$ \\
\hline & Unemployed & -0.0006 & -0.0007 \\
\hline & & $(0.0004)$ & $(0.0009)$ \\
\hline
\end{tabular}

Note: Robust std. errors. ${ }^{* *}$ Significant at $5 \%$ level

${ }^{1}$ Read: Among retaliating parents the age at which they stopped breastfeeding

is a predictor of their effort, but not of the frequency of alcohol consumption, etc. 


\section{Results}

In the model, a parent's effort increases the probability that the child will have the same socioemotional culture as the parent. The estimates are performed conditional on the cognitive skills of the parent. The following summarizes the success of the effort $\operatorname{proxies}^{11}$ :

Table 6: Success of Effort Proxies

\begin{tabular}{|c|c|c|}
\hline & Pass/Fail ${ }^{(\text {significance })}$ & Magnitude \\
\hline$\frac{\partial \pi_{A H}^{A}}{\partial e}>0$ & $\mathrm{P}^{* * *}$ & .21 \\
\hline$\frac{\partial \pi_{A L}^{A}}{\partial e}>0$ & $\mathrm{P}^{* * *}$ & .23 \\
\hline$\frac{\partial \pi_{P H}^{P}}{\partial e}<0$ & $\mathrm{P}^{* * *}$ & .45 \\
\hline$\frac{\partial \pi_{P L}^{P}}{\partial e}<0$ & $\mathrm{P}^{* * *}$ & .40 \\
\hline
\end{tabular}

A parent exerting more effort has a large marginal impact on the probability of the child adopting the parent's socioemotional culture. The model did not have any implications for the relative effect of passive parents vs. aggressive parents, but the data suggest that the effort of passive parents has about twice the impact.

The tests of the model's implications are summarized below. Though I do not find significant effects, the data support all but one of the implications. The greater the proportion of society that shares the parent's culture, the more effort the parent makes. In addition, when the parent's culture is more prominent, the probability that their child adopts their culture increases, with the exception of aggressive low-cognitive parents.

Finally, I test the role of cognitive skills. The data tell an interesting story. Though all parents increase their effort when society is more aligned with their values, high cognitive parents increase their effort less than low cognitive parents. This is intuitive because the effort of high cognitive parents is of higher quality.

\footnotetext{
${ }^{11}$ See Appendix 2 for the Maximum Likelihood estimations.
} 
Table 7: Most Implications of the Model Pass

\begin{tabular}{|c|c|}
\hline Implication & Pass/Fail (significance) \\
\hline$\frac{\partial e_{H}^{A *}}{\partial q}>0$ & $\mathrm{P}$ \\
\hline$\frac{\partial e_{L}^{A *}}{\partial q}>0$ & $\mathrm{P}$ \\
\hline$\frac{\partial e_{H}^{P *}}{\partial q}<0$ & $\mathrm{P}$ \\
\hline$\frac{\partial e_{L}^{P *}}{\partial q}<0$ & $\mathrm{P}$ \\
\hline$\frac{\partial \pi_{H}^{A A}}{\partial q}>0$ & $\mathrm{P}$ \\
\hline$\frac{\partial \pi_{L}^{A A}}{\partial q}>0$ & $\mathrm{~F}$ \\
\hline$\frac{\partial \pi_{H}^{P P}}{\partial q}<0$ & $\mathrm{P}$ \\
\hline$\frac{\partial \pi_{L}^{P P}}{\partial q}<0$ & $\mathrm{P}$ \\
\hline
\end{tabular}

Although high cognitive parents increase their effort investment by less when their culture is more prominent, the probability that the child's cultural outcome is the same as the parent's increases more for the high-cognitive parent than the low-cognitive parent. Specifically, when retaliation is more prevalent in a region, high-cognitive aggressive parents experience even greater additional success. Similarly, high-cognitive forgiving parents "lose" less frequently when retaliation is more pronounced in the local culture.

Table 8: Cognitive Skills Influence Cultural Outcome

\begin{tabular}{|c|c|}
\hline & Pass/Fail ${ }^{\text {(significance })}$ \\
\hline$\frac{\partial e_{H}^{A *}}{\partial q}<\frac{\partial e_{L}^{A *}}{\partial q}$ & $\mathrm{P}^{* * *}$ \\
\hline$\left|\frac{\partial e_{H}^{P *}}{\partial q}\right|<\left|\frac{\partial e_{L}^{P *}}{\partial q}\right|$ & $\mathrm{P}^{* * *}$ \\
\hline$\frac{\partial \pi_{A H}^{A}}{\partial q}>\frac{\partial \pi_{A L}^{A}}{\partial q}$ & $\mathrm{P}^{* * *}$ \\
\hline$\left|\frac{\partial \pi_{P H}^{P}}{\partial q}\right|<\left|\frac{\partial \pi_{P L}^{P}}{\partial q}\right|$ & $\mathrm{P}^{* * *}$ \\
\hline
\end{tabular}




\section{Conclusion}

Demonstrably, a parent's effort strongly determines a child's conflict resolution culture. The environment has a certain influence as well, but in a dynamic setting, parental effort can drive the culture of the environment. Though both resolution cultures examined in this study are psychologically justifiable, the consequences of adopting one policy over the other are drastically different depending on the social context.

\section{References}

1. The Holy Bible, containing the Old and New Testaments, Authorized King James Version. London: Cambridge University Press.

2. Becker, G.S. (1974), "A theory of social interactions," Journal of Political Economy 82, 1063-1093.

3. Becker, G.S. (1991), A Treatise on the Family, Cambridge: Harvard University Press.

4. Becker, G.S. and N. Tomes (1979), "An equilibrium theory of the distribution of income and intergenerational mobility," Journal of Political Economy 87, 1153-1189.

5. Bisin, Alberto, and Thierry Verdier. (2000) "Beyond the Melting Pot': Cultural Transmission, Marriage, and the Evolution of Ethnic and Religious Traits." Q.J.E. 115 (August): 955-88.

6. Bisin, Alberto, and Thierry Verdier. (2001), "The economics of cultural transmission and the dynamics of preferences", Journal of Economic Theory 97, 298-319.

7. Bisin, A., Topa, G. and T. Verdier (2004), "Religious intermarriage and socialization in the United States," Journal of Political Economy 112, 615-664.

8. Block, C.R. and R. Block. (1993) "Street Gang Crime in Chicago." Research in Brief (December). Washington, DC: National Institute of Justice. 
9. Borjas, G.J. (1992), "Ethnic capital and intergenerational mobility," Quarterly Journal of Economics 107, 123-150.

10. Boyd, Robert, and Peter J. Richerson. (1985) Culture and the Evolutionary Process. Chicago: Univ. Chicago Press.

11. Cornwall, Marie. (1988) "The Influence of Three Agents of Religious Socialization:Family, Church, and Peers." In The Religion and Family Connection: Social Science Perspectives, edited by Darwin L. Thomas. Provo, Utah: Brigham Young Univ. Press.

12. Cavalli-Sforza, L. and M. Feldman (1981), Cultural Transmission and Evolution. A Quantitative Approach, Princeton: Princeton University Press.

13. De Bartolome, C. (1990), "Equilibrium and inefficiency in a community model with peer group effects," Journal of Political Economy 98, 110-133.

14. Decker, Scott H., and Curry, G. David. (2002) "Gangs, gang homicides, and gang loyalty: Organized crimes or disorganized criminals" Journal of Criminal Justice 30:4 343-352.

15. Heckman, James J., and Yona Rubinstein. (2001) "The Importance of Noncognitive Skills:Lessons from the GED Testing Program.” American Economic Review 91, no.2: 145-149.

16. Ioannides, Y.M. (2002), "Nonlinear neighbourhood interactions and intergenerational transmission of human capital," In: Essays in Economic Theory, Growth and Labour Markets: A Festschrift in Honour of Emmanuel Drandakis, G. Bitros and Y. Katsoulakos

17. Ioannides, Y.M. (2003), "Empirical nonlinearities and neighbourhood effects in the intergenerational transmission of human capital," Applied Economics Letters 10, 535-539. (Eds.), Gloucester: Edward Elgar, pp. 75-112.

18. Klein, M. and C. Maxson, (1989) "Street Gang Violence." Pp. 198-234 in Violent Crimes, Violent Criminals, edited by N. Weiner. Beverly Hills: Sage. 
19. Laferrère, A. and F.-C.Wolff (2004), "Microeconomic models of family transfers," in L.- A. GérardVaret, S.-C. Kolm and J. Mercier Ythier (Eds.), Handbook on the Economics on Giving, Reciprocity and Altruism, Amsterdam: Elsevier Science, Ch. 12.

20. Leibowitz, A. (1974), "Home investments in children," Journal of Political Economy 82, S111-S131.

21. Loftin, C. 1984. "Assaultive Violence as Contagious Process." Bulletin of the New York Academy of Medicine 62:550-55.

22. Luckenbill, D. and D. Doyle. 1989. "Structural Position and Violence: Developing a Cultural Explanation." Criminology 27:419-36.

23. Maxson, M. Klein, and M. Gordon. 1985. "Differences between Gang and Nongang Homicides." Criminology 21:209-22.

24. Maxson, C. L. (1999). Gang homicide. In D. Smith \& M. Zahn (Eds.), Homicide studies: a sourcebook of social research (pp. 239-254). Newbury Park, CA: Sage.

25. Padilla, F. M. (1992). The gang as an American enterprise. New Brunswick: Rutgers.

\section{Appendix 1}

\section{Proposition 1}

$i$.

$E V_{c}^{A}=U\left(1-e^{A}\right)+\pi_{A c}^{A} W_{A}^{A}$

$E V_{c}^{A}=U\left(1-e^{A}\right)+\left[q \delta^{c} e^{A}\right] W_{A}^{A}$

F.O.C : $-U^{\prime}\left(1-e^{A}\right)+q \delta^{c} W_{A}^{A}=0$

$U^{\prime}\left(1-e^{A}\right)>0$

S.O.C : $-U^{\prime \prime}\left(1-e^{A}\right)<0$ from the assumption on $\kappa^{\prime \prime}(e)$. 
$U^{\prime}\left(1-e^{A}\right)=q \delta^{c} W_{A}^{A}$

Define $\Psi=\left[U^{\prime}\right]^{-1} . \Psi[\cdot]>0, \Psi^{\prime}[\cdot]<0$.

$$
\begin{aligned}
& 1-e^{A}=\Psi\left[q \delta^{c} W_{A}^{A}\right] \\
& e^{A *}=1-\Psi\left[q \delta^{c} W_{A}^{A}\right] \\
& \frac{\partial e^{A *}}{\partial q}=(-1) \cdot \underbrace{\Psi^{\prime}\left[q \delta^{c} W_{A}^{A}\right]}_{<0} \cdot \underbrace{\delta^{c} W_{A}^{A}}_{>0}>0
\end{aligned}
$$

ii.

$$
\begin{aligned}
& E V_{c}^{P}=U\left(1-e^{P}\right)+\pi_{P c}^{P} W_{P}^{P} \\
& E V_{c}^{P}=U\left(1-e^{P}\right)+\left[(1-q) \delta^{c} e^{P}\right] W_{P}^{P} \\
& \text { F.O.C : }-U^{\prime}\left(1-e^{P}\right)+(1-q) \delta^{c} W_{P}^{P}=0 \\
& U^{\prime}\left(1-e^{P}\right)>0 \\
& \text { S.O.C : }-U^{\prime \prime}\left(1-e^{P}\right)<0 \text { from the assumption on } \kappa^{\prime \prime}(e) \text {. } \\
& U^{\prime}\left(1-e^{P}\right)=(1-q) \delta^{c} W_{P}^{P} \\
& 1-e^{P}=\Psi\left[(1-q) \delta^{c} W_{P}^{P}\right], \Psi=\left[U^{\prime}\right]^{-1} \\
& e^{P *}=1-\Psi\left[(1-q) \delta^{c} W_{P}^{P}\right] \\
& \frac{\partial e^{p *}}{\partial q}=(-1) \cdot \underbrace{\Psi^{\prime}\left[(1-q) \delta^{c} W_{P}^{P}\right]}_{<0} \cdot(-1) \cdot \underbrace{\delta^{c} W_{P}^{P}}_{>0}<0
\end{aligned}
$$

\section{Proposition 2}

iii.

$$
\begin{aligned}
& \pi_{A c}^{A}=q \delta^{c} e_{c}^{A}[q] . \\
& \frac{\partial \pi_{A c}^{A}}{\partial q}=\underbrace{\frac{\partial e^{A}[q]}{\partial q}}_{>0} \cdot \underbrace{q \delta^{c}}_{>0}+\underbrace{e_{c}^{A}[q]}_{>0} \cdot \underbrace{\delta^{c}}_{>0}>0
\end{aligned}
$$


$i v$.

$$
\begin{aligned}
& \pi_{P c}^{P}=(1-q) \delta^{c} e_{c}^{P}[q] . \\
& \frac{\partial \pi_{c}^{P P}}{\partial q}=\underbrace{\frac{\partial e^{P}[q]}{\partial q}}_{<0} \cdot \underbrace{(1-q) \delta^{c}}_{>0}+\underbrace{e^{P}[q]}_{>0} \cdot \underbrace{-\delta^{c}}_{<0}<0
\end{aligned}
$$

\section{Appendix 2}

Table 9: Socialization to Retaliation (Joint ML)

\begin{tabular}{ccc}
\hline \hline Stage 1 Dependent Var: effort $e^{A}$ & $\mathrm{~N}=174$ & $\mathrm{~N}=230$ \\
& Hi Cognitive & Low Cognitive \\
Instrument & -0.0333 & $-0.0019^{* *}$ \\
& $(0.0218)$ & $(0.0010)$ \\
$q$ & 0.0457 & 1.4830 \\
& $(4.248)$ & $(3.2265)$ \\
\hline
\end{tabular}

Stage 2 Dependent Var: $\pi^{A A}$

\begin{tabular}{ccc} 
& Hi Cognitive & Low Cognitive \\
& 0.9734 & -1.2205 \\
Effort & $(4.0774)$ & $(3.1352)$ \\
& $1.3975^{* * *}$ & $1.5385^{* * *}$ \\
& $(0.1677)$ & $(0.1172)$ \\
\hline
\end{tabular}

Note: Robust std. errors are in parentheses. 
Table 10: Socialization to Reconciliation (Joint ML)

\begin{tabular}{ccc}
\hline \hline Stage 1 Dependent Var: effort $e^{P}$ & $\mathrm{~N}=569$ & $\mathrm{~N}=430$ \\
& & \\
Instrument & Hi Cognitive & Low Cognitive \\
& $0.1846^{* *}$ & 0.0874 \\
$q$ & $(0.0740)$ & $(0.1042)$ \\
& -0.1854 & -4.0849 \\
& $(2.3317)$ & $(2.9784)$ \\
\hline
\end{tabular}

Stage 2 Dependent Var: $\pi^{P P}$

\begin{tabular}{ccc} 
& Hi Cognitive & Low Cognitive \\
& -1.7502 & -2.4108 \\
& $(2.1579)$ & $(2.8003)$ \\
Effort & $1.4779^{* * *}$ & $1.4589^{* * *}$ \\
& $(0.0741)$ & $(0.1512)$ \\
\hline
\end{tabular}

Note: Robust std. errors are in parentheses. 